\title{
Metformin and trametinib have synergistic effects on cell viability and tumor growth in NRAS mutant cancer
}

\author{
Igor Vujic ${ }^{1,2}$, Martina Sanlorenzo ${ }^{1,3}$, Christian Posch ${ }^{1,2}$, Rosaura Esteve-Puig ${ }^{1}$, Adam \\ J. Yen ${ }^{1}$, Andrew Kwong ${ }^{1}$, Aaron Tsumura ${ }^{1}$, Ryan Murphy ${ }^{1}$, Klemens Rappersberger ${ }^{2}$ \\ and Susana Ortiz-Urda ${ }^{1}$ \\ ${ }^{1}$ University of California, San Francisco, Department of Dermatology, Mt. Zion Cancer Research Center, San Francisco, CA, \\ USA \\ ${ }^{2}$ Rudolfstiftung Hospital, Academic Teaching Hospital, Department of Dermatology, Juchgasse, Vienna, Austria \\ ${ }^{3}$ Department of Medical Sciences, Section of Dermatology, University of Turin, Italy \\ Correspondence to: Igor Vujic, email: igor.vujic.md@gmail.com
}

Keywords: NRAS, metformin, trametinib, combination therapy

Received: October 08, $2014 \quad$ Accepted: November 24, $2014 \quad$ Published: November 25, 2014

This is an open-access article distributed under the terms of the Creative Commons Attribution License, which permits unrestricted use, distribution, and reproduction in any medium, provided the original author and source are credited.

\section{ABSTRACT}

Attempts to directly block the mutant neuroblastoma rat sarcoma oncogene (NRAS) protein, a driving mutation in many cancer types, have been unsuccessful. Current treatments focus on inhibition of different components of NRAS' two main downstream cascades: PI3K/AKT/mTOR and MAPK. Here we test a novel dual therapy combination of metformin and trametinib on a panel of 16 NRAS mutant cell lines, including melanoma cells, melanoma cells with acquired trametinib resistance, lung cancer and neuroblastoma cells. We show that both of the main downstream cascades of NRAS can be blocked by this combination: metformin indirectly inhibits the PI3K/ AKT/mTOR pathway and trametinib directly impedes the MAPK pathway. This dual therapy synergistically reduced cell viability in vitro and xenograft tumor growth in vivo. We conclude that metformin and trametinib combinations are effective in preclinical models and may be a possible option for treatment of NRAS mutant cancers.

\section{INTRODUCTION}

Mutations in the neuroblastoma rat sarcoma viral oncogene (NRAS) play an important role in cancer. NRAS mutations are found in $15-20 \%$ of malignant melanomas, but also in several other cancer types [1-5]. These point mutations usually affect codons 12, 13 (Exon I) and 61 (Exon II) of the NRAS gene. The mutant NRAS protein constitutively activates downstream signaling cascades such as the MAPK, PI3K/AKT/mTOR and Ral pathways, resulting in uncontrolled cell proliferation and tumor growth $[1,6,7]$. Attempts to directly inhibit mutant NRAS have been unsuccessful so far. Treatment approaches use small molecule inhibitors which interfere with NRAS downstream pathways [8-10]. Mitogen-activated protein kinase kinase (MEK) inhibitors block signaling through the MAPK pathway and NRAS mutated tumors are associated with MEK inhibitor efficacy [11]. The MEK inhibitor trametinib has shown clinical efficacy in patients with NRAS mutant cancers [9].
Given the activation and the crosstalk of MAPK and $\mathrm{PI} 3 \mathrm{~K} / \mathrm{AKT} / \mathrm{mTOR}$ pathways in NRAS mutant tumors, and the development of resistance to monotherapies, there is a strong rationale for a dual pathway inhibition. Various inhibitor combinations have shown preclinical efficacy and are currently being evaluated in trials $[5,9,10,12-14]$. So far, the outcomes are only modest and the use of such combinations is partly limited by serious adverse events [15-17].

On the other hand, colleagues report encouraging preliminary results on trials testing metformin alone or in combination with vemurafenib in $B R A F^{V 600}$ mutant melanoma (NCT01840007; NCT01638676) [18]. Metformin is a biguanide which has been used as an oral anti-diabetic drug for decades and has a well-known safety profile. In addition to its effects on glucose metabolism, it ultimately inhibits mTOR in cancer cells and leads to growth arrest and apoptosis $[19,20]$. Retrospective studies report a decrease in cancer risk and lower cancer mortality in diabetic patients treated with metformin 
[21-24]. A recent meta-analysis includes 65,540 cancer cases in diabetic patients and shows that the cancer incidence and mortality in those taking metformin was reduced. However, the authors state that the results varied significantly across studies and that prospective studies in non-diabetic patients are needed to understand metformin's effect on cancer [25].

Consequently, we explore if metformin could be a potential partner of trametinib for the treatment of $N R A S$ mutant tumors. The combination would lead to a desirable dual pathway inhibition. We use a large panel of $N R A S$ mutant melanoma, neuroblastoma and lung cancer cell lines. We show that the combination of metformin and trametinib has a synergistic effect in NRAS mutant tumors and reduces tumor size in a xenograft model. In addition, we investigate the effect of metformin on two $N R A S$ mutant melanoma cell lines with acquired resistance to trametinib.

\section{RESULTS}

\section{Effects of metformin and trametinib on NRAS mutant melanoma cells}

To evaluate the response of $N R A S$ mutant melanoma to metformin and trametinib, we first performed CTG-cell
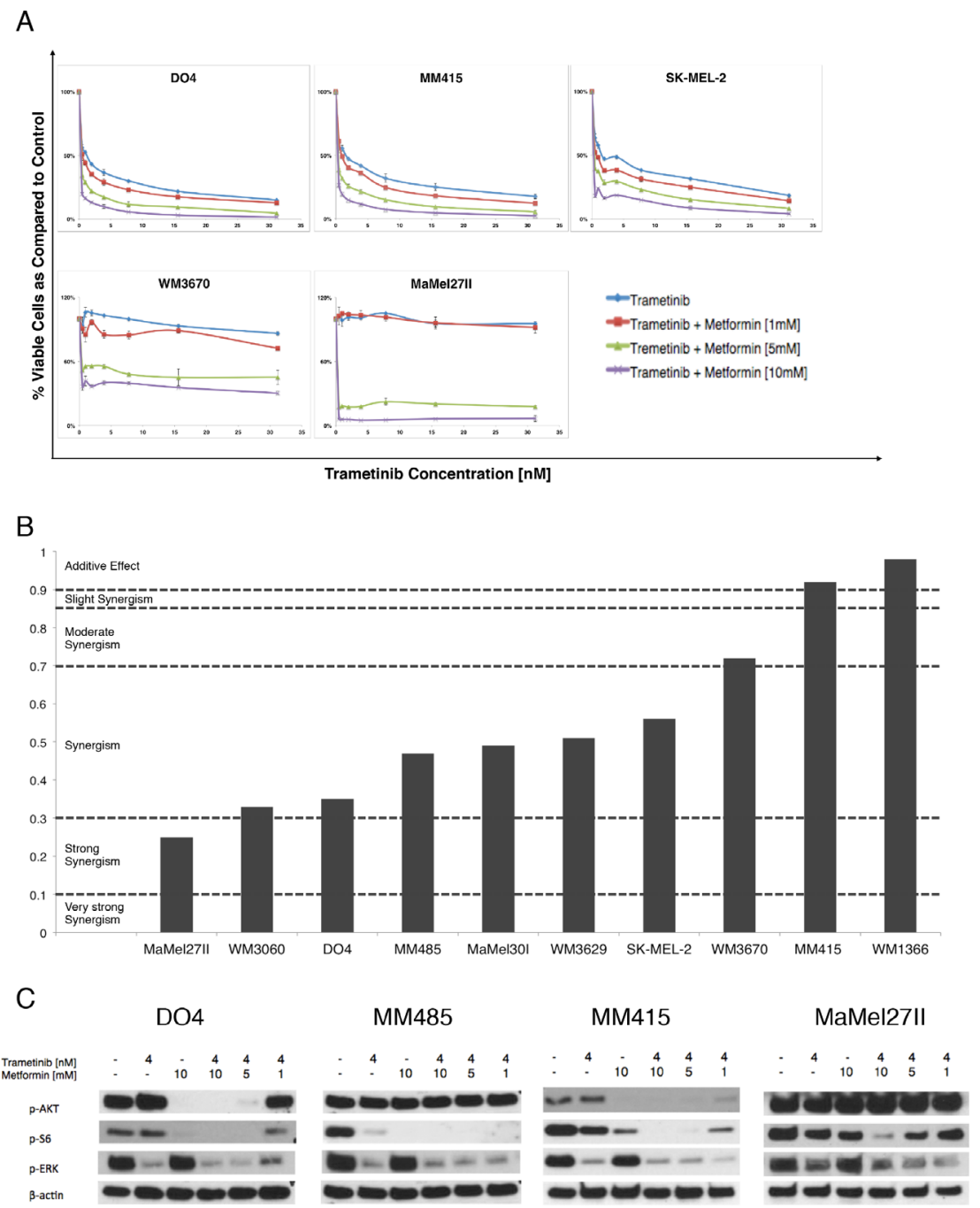

Figure 1: Metformin and trametinib have synergistic effects on cell viability in NRAS mutant melanoma cells. (A) Representative dose response curves for trametinib and its combination with metformin in different ratios. The addition of metformin to trametinib leads to a downward shift of the dose response curves in all cell lines tested ( $\mathrm{n}=3$, incubation $72 \mathrm{hrs}$, error bars represent SD). (B) Combination index (CI) values for metformin and trametinib. The CI values were calculated using the CalcuSyn software according to the recommendations of Chou-Talalay. The drugs show synergism in all cell lines except MM415 and WM1366 where they have an additive effect [26] (C) Immunoblot analyses for downstream effector proteins of the MAPK and PI3K/AKT/mTOR signaling pathways. Cells were treated with metformin, trametinib or their combinations (incubation 4 hrs.). Dual pathway inhibition is achieved by combining metformin and trametinib, as evidenced by the decrease of p-ERK and p-S6. 
Table 1: Growth inhibitory effects of metformin and trametinib in NRAS mutant cancer cell lines. The table displays concentrations of drugs resulting in 50\% decrease of cell viability relative to untreated controls (GI50). Drug concentrations ranged from 0.1-20mM for metformin and 0.2-30nM for trametinib.

\begin{tabular}{|l|l|l|l|l|}
\hline Cell Line & Tissue & NRAS mutation & $\begin{array}{l}\text { GI50 } \\
\text { trametinib [nM] }\end{array}$ & $\begin{array}{l}\text { GI50 } \\
\text { metformin [mM] }\end{array}$ \\
\hline DO4 & Melanoma & Q61L & 0.7 & 5.2 \\
\hline MM415 & Melanoma & Q61L & 1.3 & 7.15 \\
\hline WM1366 & Melanoma & Q61L & 55.9 & 4.36 \\
\hline SK-MEL-2 & Melanoma & Q61K & 0.67 & 5.32 \\
\hline WM3060 & Melanoma & Q61K & 1.94 & 9.96 \\
\hline MM485 & Melanoma & Q61R & 1.2 & 14.45 \\
\hline MaMe130I & Melanoma & G13D & 15.66 & 5.52 \\
\hline MaMe127II & Melanoma & G12D & $>100$ & 6.4 \\
\hline WM3629 & Melanoma & G12D & 9.92 & 3.39 \\
\hline WM3670 & Melanoma & G12D & 52.0 & 9.3 \\
\hline DO4-RM & Melanoma & Q61L & 23.3 & $10.16^{\mathrm{a}}$ \\
\hline MM415-RM & Melanoma & Q61L & $>100$ & $3.22^{\text {a }}$ \\
\hline SW-1271 & Lung carcinoma & Q61R & 26.8 & 29.9 \\
\hline NCI-H2347 & Lung carcinoma & Q61R & 82.0 & 6.79 \\
\hline SK-N-AS & Neuroblastoma & Q61K & 5.82 & 3.52 \\
\hline CHP-212 & Neuroblastoma & Q61K & 0.26 & 1.11 \\
\hline
\end{tabular}

${ }^{\text {a }}$ Experiments in DO4-RM and MM415-RM cells with acquired trametinib resistance were performed in the presence of $5 \mathrm{nM}$ and $55 \mathrm{nM}$ trametinib, respectively.

viability assays. We incubated a panel of 10 cell lines with previously characterized mutations [12] with the respective drugs and their combinations. The cell lines, their mutations and GI50 values (concentrations of drugs resulting in $50 \%$ decrease in cell viability relative to controls) for the single agent drugs are reported in Table 1. The GI50 values in treatment-naïve melanoma cells ranged from 3.39 to $14.45 \mathrm{mM}$ with an average value of $7.11 \mathrm{mM}$ for metformin and from 0.67 to $>100 \mathrm{nM}$ for trametinib. All cell lines showed more cell viability decrease when the drugs were combined (Figure 1A).

To analyze whether the combination leads to inhibition of cell proliferation or cell death, we studied the induction of apoptosis or necrosis by staining the cells with Annexin V/Propidium Iodide assay followed by flow cytometry (Supplementary Figure S1). These assays also served as a control to the CTG assay, which measures total ATP levels in cells and might report incorrect measurements of cell viability, especially when mitochondrial complex I inhibitors like metformin are used. The apoptosis assays showed that the combination leads to cell death and they confirmed the synergistic results of the CTG assays.

To quantify the effect of the combination, we used Calcusyn software to calculate the combination index (CI) for all melanoma cell lines. The CI values ranged from 0.25 for MaMel27II to 0.98 for WM1366 (Figure 1B). Most cell lines had a CI index between 0.3 and 0.7 indicating synergism according to the method of ChouTalalay [26]. The combination showed an additive effect in cell lines MM415 and WM1366 who had a CI index above 0.9. No cell line showed an antagonistic effect to the combination therapy.

Next, we analyzed the effect of the drugs and their combinations on the two main NRAS downstream signaling pathways MAPK and PI3K/AKT/mTOR. Metformin showed an effect on the PI3K/AKT/mTOR pathway, where it inhibited the phosphorylation of S6 in a dose-dependent manner. In cell lines DO4 and MM415 metformin also inhibited AKT phosphorylation. Trametinib led to an inhibition of ERK phosphorylation in all cell lines tested. The combination of metformin and trametinib suppressed the phosphorylation of NRAS effector proteins ERK and S6, providing an explanation of the effects on cell viability (Figure 1C).

\section{Effects of metformin and trametinib on non- melanoma NRAS mutant lung cancer and neuroblastoma}

Since NRAS shares signaling similarities across different malignancies, we hypothesized that the effects of the combination might be translated to NRAS mutant cancers other than melanoma [10]. For these experiments we used two neuroblastoma and two lung cancer cell lines with known $N R A S^{Q 61}$ mutations and dependency on NRAS signaling [10]. Metformin and trametinib had comparable effects on cell viability and pathway inhibition as in NRAS mutant melanoma cell lines (Figure 2 A,B). 


\section{Metformin effects on $N R A S$ mutant cell lines resistant to trametinib}

Resistance to single agent inhibitors, such as trametinib, is a growing concern. Metformin decreased cell viability in cell lines WM3670 and MaMel27II with relatively innate trametinib resistances (Table 1, Figure 1A). Therefore, we tested metformin on trametinibresistant cell lines DO4-RM and MM415-RM, where it decreased cell viability in both clones. The analysis of NRAS downstream effector proteins showed a dosedependent decrease of AKT or S6 phosphorylation (Figure $3 \mathrm{~A}, \mathrm{~B})$.

\section{Effects of metformin and trametinib on a human melanoma xenograft model}

Given the promising in vitro results, we examined the effect of the combination in a xenograft model. Human DO4 cells were injected subcutaneously into nude mice, and gave rise to tumors in 1-2 weeks. Treatment with either metformin or trametinib decelerated tumor growth compared to vehicle treated controls. Combination therapy led to less tumor growth compared to single-drug therapy and vehicle treated controls. (Figure 4A).

The difference in relative tumor volumes was statistically significant comparing the combination group with the three other groups (vehicle, metformin only, trametinib only) on days 15 and 22 after treatment began

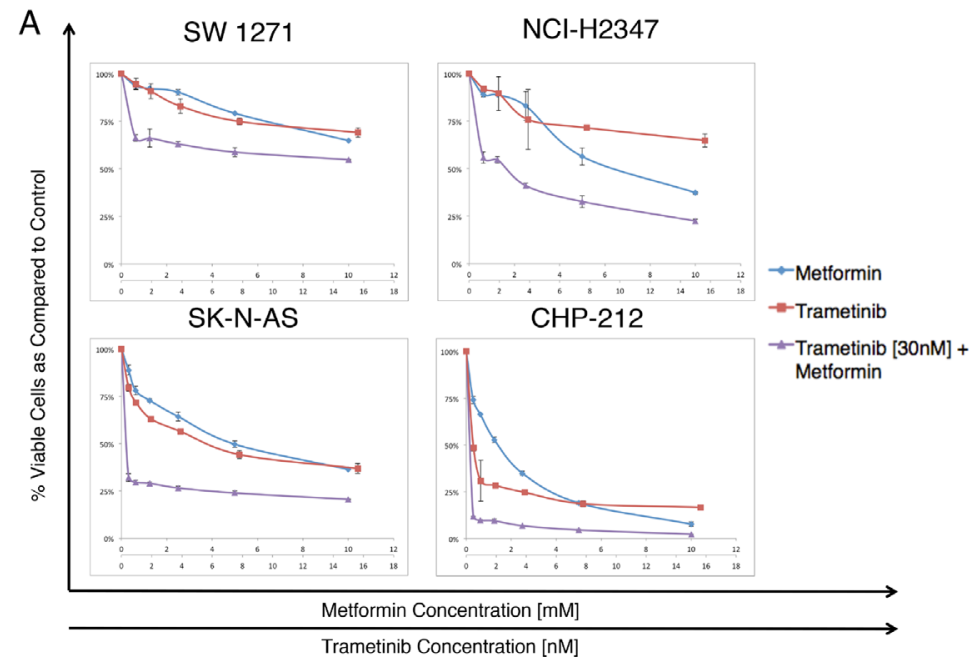

B

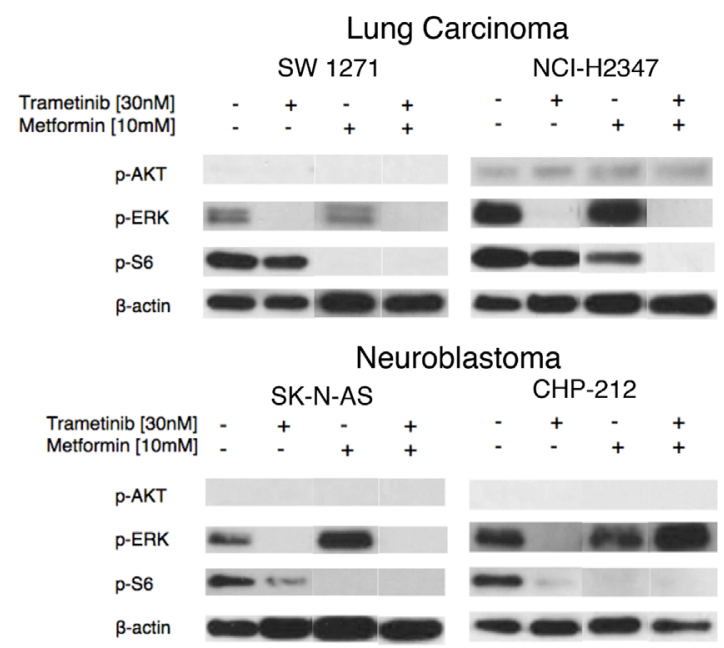

Figure 2: Metformin and trametinib effects on NRAS mutant lung cancer and neuroblastoma cells . (A) Dose response curves for two lung carcinoma and two neuroblastoma cell lines with known activating NRAS mutations ( $\mathrm{n}=3$, incubation $72 \mathrm{hrs}$, error bars represent SD). The combination is more effective in reducing cell viability than each of the agents alone. (B) Cropped immunoblot analyses for downstream effector proteins of the MAPK and PI3K/AKT/mTOR signaling pathways for NRAS ${ }^{\mathrm{Q} 61}$ mutant lung carcinoma and neuroblastoma cell lines. Dual pathway inhibition can be achieved by combining metformin and trametinib, as evidenced by the abolishment of p-ERK and p-S6. 
A
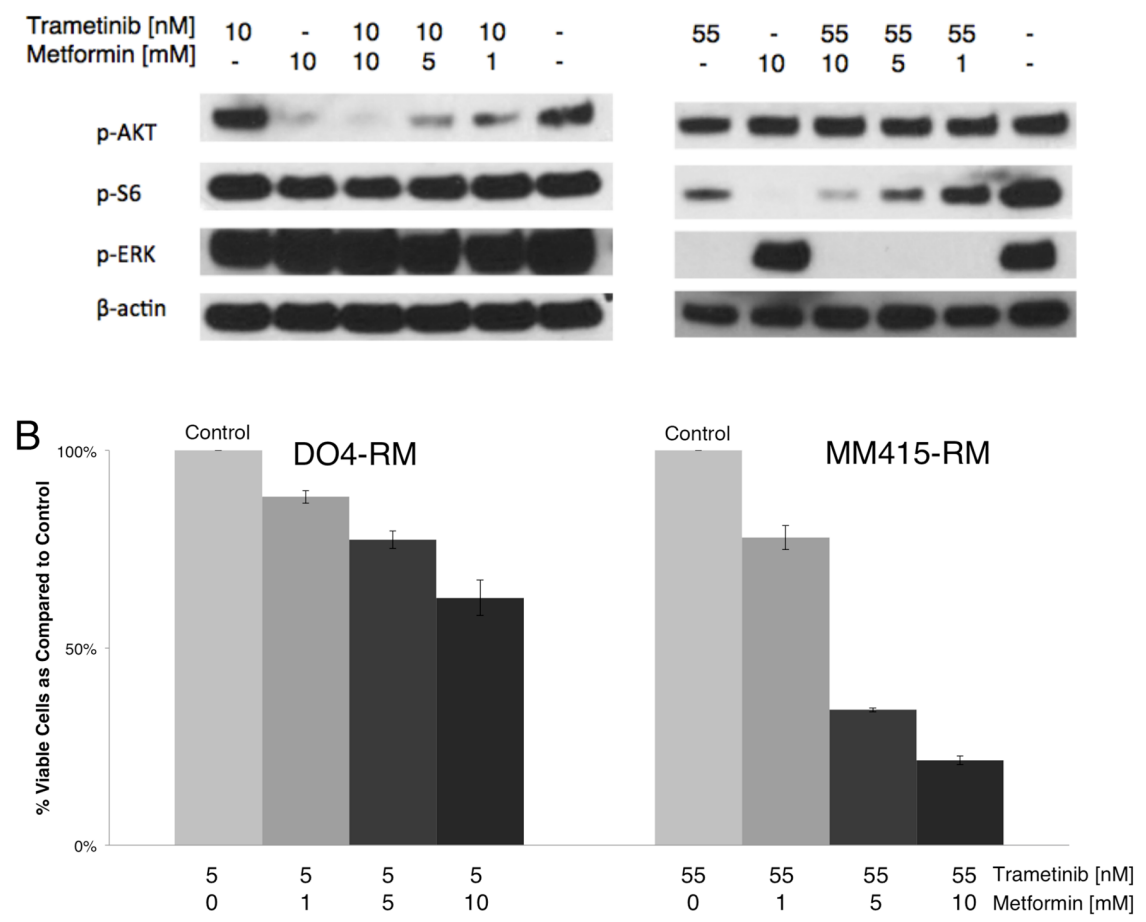

Figure 3: NRAS mutant melanoma cell lines with an acquired resistance to trametinib show cell viability decrease to single agent metformin. (A) Immunoblot analyses of downstream effectors of NRAS mutant melanoma cells with acquired resistance to trametinib. Metformin decreases p-AKT in DO4-RM and p-S6 in MM415-RM in a dose-dependent manner. (B) Decrease of cell viability in trametinib-resistant cell lines DO4-RM and MM415-RM after treatment with metformin. Bars represent percentages of viable cells compared to controls (Incubation $72 \mathrm{hrs}, \mathrm{n}=3$, error bars represent $\mathrm{SD}$ ).

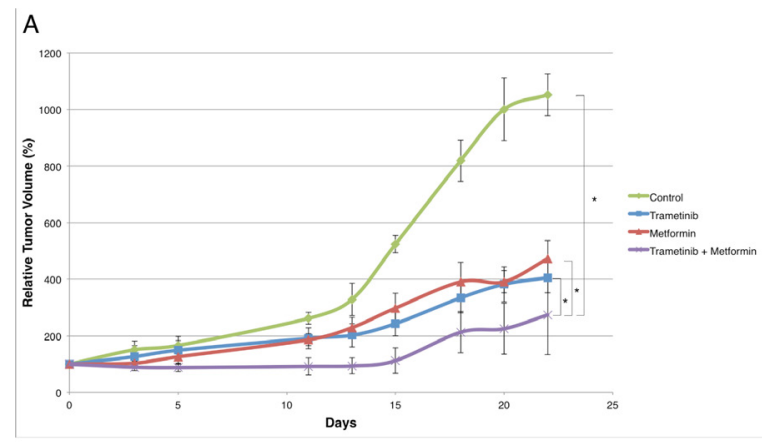

B

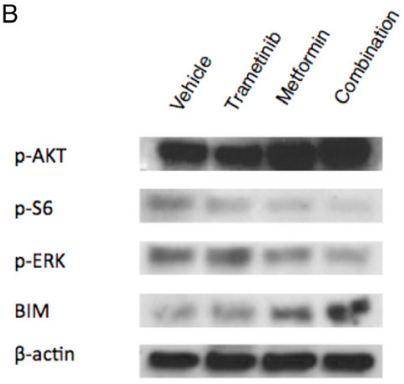

Figure 4: Relative tumor volume and immunoblot analyses for the respective treatment groups in a DO4 melanoma xenograft model. (A) Growth curves of DO4 NRAS mutant melanoma in a xenograft model are shown. DO4 cells were implanted subcutaneously into nude mice and treatment was started when tumor volumes reached approximately $100 \mathrm{~mm}^{3}$. Metformin and trametinib combination inhibits tumor growth more than each drug alone. The results remain statistically significant after 22 days $(\mathrm{n}>3, * \mathrm{p}<.05$, treatment start at day 0). (B) Immunoblot analyses of downstream effector proteins in DO4 xenograft tumors. The combination of metformin and trametinib leads to a stronger decrease of NRAS downstream effectors p-ERK and p-S6, and to induction of the pro-apoptotic protein BIM. 
$(p<.05$; ANOVA, Bonferroni correction). However, there was no significant difference in tumor suppression when comparing the two single treatment groups with each other ( $p=0.578$, day $15 ; p=1.0$, day22). Target inhibition was assessed by immunoblotting of xenograft tumor tissue. The combination treatment suppressed NRAS downstream effectors more potently than single-drug treatment. Additionally, the combination of metformin and trametinib caused an induction of the pro-apoptotic protein BIM (Figure 4B).

\section{DISCUSSION}

Diabetes is associated with an increased risk of having certain cancers [27]. However, diabetic patients who take the blood glucose lowering metformin have lower cancer incidence, lower cancer related mortality, and lower risk of cancer development, compared to diabetics treated with other agents $[18,21]$. In one prospective trial metformin reduced the number of pre-cancerous lesions in the rectum, suggesting a preventive role of metformin in the development of rectal cancer [28].

The biguanide metformin is widely prescribed and has a well-known safety profile. In cancer cells, metformin interferes with the PI3K/AKT/mTOR pathway, and indirectly inhibits mTOR. It leads to cell cycle arrest, increased apoptosis and autophagy [18-20,29]. This makes metformin an attractive candidate for the treatment of NRAS mutant cancer, where the constitutively active NRAS signals through the PI3K/AKT/mTOR pathway.

This study evaluates the effects of the combination of metformin and the MEK inhibitor trametinib in NRAS mutant cancer. We focus our efforts on NRAS mutant melanoma, but also show that the same principles apply in other cancers with known oncogenic NRAS mutations. NRAS mutations are rare in lung cancer and neuroblastoma. However, the high prevalence of these tumors makes their NRAS mutant form clinically very relevant [10].

Several studies report inhibitory effects in different cancer types using AMPK activators like metformin, AICAR or phenformin, alone or in combination with other drugs such as erolotinib or dasatinib [30-38]. Whether $B R A F^{V 600}$ mutant and NRAS mutant melanoma cells have differing sensitivities to metformin is a matter of debate. While some authors show that the induction of autophagy and apoptosis is independent of the $B R A F$ or NRAS mutation status of cells, others report that metformin increases tumor growth of $B R A F$ mutated melanoma xenografts by up-regulation of VEGF-A and induction of angiogenesis [30-32]. In our hands, metformin inhibits cell growth and induces apoptosis in $N R A S$ mutant melanoma, neuroblastoma and lung cancer with GI50 values ranging between $1.11 \mathrm{mM}$ and $29.9 \mathrm{mM}$ (Table 1, Figure 1). Our results are supported by other studies, strengthening the rationale for metformin use in
$N R A S$ mutant cancers [30-32,39]. As previously shown, all NRAS mutant cells used in this study depend upon the NRAS mutation. Still, variations to what extent the typical downstream cascades of mutant NRAS account for survival and proliferation exist. This might, at least in part, explain the observed differences in sensitivity to the inhibitory agents used in this study.

Mutant NRAS constitutively signals through the MAPK and PI3K/AKT/mTOR pathways, among others. Mounting evidence suggests that dual inhibition of both pathways may lead to better results in NRAS mutant cancer $[10,12,14]$. NRAS mutations are associated with MEK inhibitor efficacy and first clinical results with MEK inhibitors show a response rate of $20 \%$ in patients with advanced $N R A S$ mutant melanoma $[11,40]$. Here, we show that metformin and trametinib synergistically decrease cell viability in a large survey of NRAS mutant melanoma, lung cancer and neuroblastoma cell lines, including two cell lines with acquired trametinib resistance. The finding of synergism in different cancer types with activating $N R A S$ mutations is not surprising, because NRAS mutant melanoma, lung cancer and neuroblastoma all seem to depend on NRAS downstream signaling through MAPK and PI3K/AKT/mTOR $[3,10]$. Trametinib inhibits the MAPK pathway while metformin inhibits the PI3K/AKT/ mTOR pathway. The combination of the two produces a synergistic effect because they lead to dual pathway inhibition of NRAS's important signaling pathways. Our immunoblots verified the dual pathway inhibition by the combination, and showed a reduction in NRAS downstream cascade effector proteins p-AKT, p-S6, and p-ERK.

Resistance to targeted inhibitors is a growing concern in the field of oncology, and multiple mechanisms of such resistance are known [41-43]. We show the effect of metformin on cells with an acquired resistance to trametinib and hypothesize that its addition to trametinib might delay or reverse the development of resistance. Blocking targets in the $\mathrm{PI} 3 \mathrm{~K} / \mathrm{AKT} / \mathrm{mTOR}$ pathway by different drugs can reverse resistance to inhibitors of MAPK signaling cascade components, as shown by other authors in melanoma [44].

Certain questions should be addressed before metformin is used in combination therapy on patients. Metformin doses used in in vitro studies are higher than serum levels observed in diabetic patients ( 1 to $20 \mathrm{umol} / \mathrm{L}$ ) [45]. Yet, retrospective epidemiologic studies and metaanalyses still showcase the anti-tumor effects of metformin $[22-25,46]$. A possible explanation of the in vivo effect of the drug is the accumulation of positively charged metformin in certain tissues and within the mitochondria. This can lead to local concentrations $>1000$ fold higher than the serum levels [47-49]. Also, the mechanism of metformin's in vivo effects has not been fully understood. Beyond the blockage of the PI3K/AKT/mTOR signaling pathway, metformin could interfere with insulin signaling 
and lower serum glucose [27,50,51]. Here, immunoblots of xenograft tumors showed some blockage of NRAS downstream pathways when metformin was used. Combination therapy on mouse xenograft tumors showed tumor volumes significantly lower than those of the control and single treatment groups for the entirety of treatment, but we could not abolish tumor growth completely with either treatment.

Further studies are needed to elucidate the in vivo action of metformin, but our study provides evidence that a combination of metformin and trametinib may be a possible option for treatment of $N R A S$ mutant cancers.

\section{METHODS}

\section{Cell lines, cell culture}

Human NRAS mutant melanoma cell lines DO4, MM415, MM485, SK-MEL-2, MaMel30I and MaMel27II were a generous gift from Boris Bastian at the University of California, San Francisco (UCSF); cell lines WM1366 (Cat N. WC00078), WM3629 (Cat N. WC00117), WM3670 (Cat N. WC00119) and WM3060 (Cat N. WC00126) were obtained from Coriell Institute (Wistar Institute, Philadelphia, PA, USA). NRAS mutant lung carcinoma cell lines SW1271, NCI-H2347 and neuroblastoma cell lines SK-N-AS and CHP212 were purchased from American Type Culture Collection (Oct/2013). Cell lines were not authenticated by short tandem repeat DNA profiling after purchase, but were regularly tested for NRAS mutation status.

Cell lines DO4, MM415, MM485, SK-MEL-2, MaMel30I, MaMel27II, SW1271, NCI-H2347, SK-NAS and CHP212 were cultured in RPMI-1640 media supplemented with $10 \%$ ( $\mathrm{vol} / \mathrm{vol})$ heat inactivated fetal bovine serum (FBS); cell lines WM1366, WM3629, WM3670 and WM3060 were cultured in MCDB153 media supplemented with 20\% (vol/vol) Leibovitz's L-15 media, 2\% (vol/vol) FBS, and $1.68 \mathrm{mM} \mathrm{CaCl} 2$. All cell lines were incubated at $37{ }^{\circ} \mathrm{C}$ under $5 \% \mathrm{CO} 2$.

\section{Establishment of trametinib resistant cell lines DO4-RM and MM415-RM}

We treated cell lines D04 and MM415 with trametinib dosages corresponding to their respective GI50 values and increased trametinib concentrations over a period of approximately 6 months. Surviving clones were selected for and further propagated. The established resistant cell lines were termed DO4-RM and MM415RM were maintained in RPMI 1640 media supplemented with $10 \%$ (vol/vol) FBS and $5 \mathrm{nM}$ or $55 \mathrm{nM}$ trametinib, respectively (Supplementary Figure S2).

\section{Drugs, cell viability assays, apoptotic assays}

Trametinib and metformin were purchased from Selleck Chemicals (Houston, Texas, USA). For cell viability assays, cells were plated in 96-well plates with a density of 4000-8000 cells per well and incubated for 24 $\mathrm{h}$ at $37{ }^{\circ} \mathrm{C}$ with $5 \% \mathrm{C} 02$. Then cells were incubated with increasing drug concentrations and their combinations. Cell viability was measured with the CellTiter-Glo (CTG) Luminescent Cell Viability Assay (Promega; Madison, Wisconsin, USA) according to the manufacturer's protocol. Luminescence was measured on the SynergyHT plate reader (BioTek, Vermont, USA) using Gen5 software (Version 1.11.5). For apoptotic assays, cells were plated in 12-well plates and treated with DMSO, trametinib, metformin or combinations. After $72 \mathrm{hrs}$ apoptosis was assessed using the Dead Cell Apoptosis Kit with Annexin V Alexa Fluor 488 \& Propidium Iodide according to the manufacturer's protocol (Invitrogen; V13241) with the AccuriC6 Flow Cytometer using the CFlow software (Version 1.0.227.4).

\section{GI50 values, Combination index}

Concentrations of drugs resulting in 50\% decrease in cell viability relative to controls (GI50) as well as the combination index (CI) were calculated using CalcuSyn software (Biosoft, Cambridge, UK; Version 2.1). According to the recommendation of Chou-Talalay, a CI $<0.9$ indicated synergistic effects of drugs; the synergism was further refined as: slight synergism $(\mathrm{CI}=0.85-0.9)$, moderate synergism $(\mathrm{CI}=0.7-0.85)$, synergism $(\mathrm{CI}=0.3$ $0.7)$, strong synergism $(\mathrm{CI}=0.1-0.3)$ and very strong synergism $(\mathrm{CI}<0.1)[26]$.

\section{Western Blotting}

Cells were washed with ice cold phosphate buffered saline (PBS), lysed using radio-immunoprecipitation (RIPA) buffer [150mM NaCl, 1\% (vol/vol) Nonidet $\mathrm{P}-40,0.5 \%$ (wt/vol) sodium deoxycholate, $0.1 \%$ (wt/ vol) $\mathrm{SDS}$ ] in 50mM Tris $\mathrm{HCl}(\mathrm{pH} 8.0)$ supplemented with protease and phosphatase inhibitors (Pierce, IL, USA; 78442). Protein concentrations were determined using the BCA Protein Assay kit (Pierce; 23225) according to the manufacturer's protocol. Proteins were separated by SDSPAGE with 4-20\% gradient gels (Bio-Rad Laboratories, CA, USA; 456-1096), transferred to an Immobilon-P PVDF membrane (Millipore, MA, USA; IPVH00010), and blocked in 5\% dry milk in Tris Buffered Saline, with Tween 20 (TBST) (Sigma-Aldrich). Membranes were incubated with primary and secondary antibodies, and target proteins were detected with ECL detection reagent (Pierce; 32106). $\beta$-Actin (Sigma-Aldrich) served as a 
loading control. Phospho-ERK (4370), phospho-AKT (4060), phospho-S6 (4857), Bim (2933) antibodies were obtained from Cell Signaling Technology (MA, USA).

\section{Tumor xenografts in nude mice}

Six-week-old female CrTac:NCr-Foxn1 ${ }^{n u}$ mice (Taconic Farms, USA; weight 20-25g) were injected subcutaneously with $6 \times 10^{6} \mathrm{DO} 4$ cells re-suspended in 200ul Matrigel (BD Biosciences, USA). Treatment was started when tumors reached approximately $100 \mathrm{~mm}^{3}$. Mice were treated once daily, five days per week, with either oral vehicle (methylcellulose $0.5 \%$, Tween 80 $0.2 \%$; oral gavage), trametinib ( $2 \mathrm{mg} / \mathrm{kg} / \mathrm{day}$, oral gavage), D-PBS (200ul; intraperitoneal injection) or metformin $(200 \mathrm{mg} / \mathrm{kg} /$ day; intraperitoneal injection). The change in tumor size was measured with calipers every 2-4 days, and the tumor volume was calculated using the formula $\mathrm{V}=\pi \times \mathrm{a} \times \mathrm{b} \times \mathrm{c} \times 4 / 3$. After 22 days of treatment mice were euthanized. Tumors were collected, pulverized in liquid nitrogen, lysed and subjected to western blotting as described above. All mouse studies were approved by the UCSF Institutional Animal Care and Use Committee (Protocol \# AN086990-03A).

\section{ACKNOWLEDGMENTS}

This work was supported by National Cancer Institute of the National Institutes of Health (Grant number: K08CA155035; S. Ortiz-Urda), and the Melanoma Research Alliance (Young Investigator Award 273564; S. Ortiz-Urda). The content is solely the responsibility of the authors and does not necessarily represent the official views of the National Institutes of Health. The authors thank Boris Bastian for providing the cell lines used in this study. The authors are also grateful to Timothy Dattels and the Verein für Dermatologie Krankenanstalt Rudolfstiftung for their generous support.

\section{REFERENCES}

1. Schubbert S, Shannon K, Bollag G. Hyperactive Ras in developmental disorders and cancer. Nat Rev Cancer. 2007; 7: 295-308

2. Howlader N, Noone AM, Krapcho M, Garshell J, Neyman N, Altekruse SF, Kosary CL, Yu M, Ruhl J, Tatalovich Z, Cho H, Mariotto A, Lewis DR, et al. SEER Cancer Statistics Review, 1975-2010. National Cancer Institute [Internet]. 2013 [cited 2013 Sep 14]. Available from: http:// seer.cancer.gov/csr/1975_2010/

3. Ohashi K, Sequist LV, Arcila ME, Lovly CM, Chen $\mathrm{X}$, Rudin CM, Moran T, Camidge DR, VnencakJones CL, Berry L, Pan Y, Sasaki H, Engelman JA, et al. Characteristics of Lung Cancers Harboring NRAS Mutations. Clin Cancer Res. 2013; 19: 2584-91.
4. Comprehensive Cancer Information. National Cancer Institute [Internet]. [cited 2014 Mar 31]. Available from: http://www.cancer.gov/

5. Johnson DB, Smalley KSM, Sosman JA. Molecular Pathways: Targeting NRAS in Melanoma and Acute Myelogenous Leukemia. Clin Cancer Res. 2014; 20: 418692.

6. Bos JL. ras oncogenes in human cancer: a review. Cancer Res. 1989; 49: 4682-9.

7. Fedorenko IV, Gibney GT, Smalley KSM. NRAS mutant melanoma: biological behavior and future strategies for therapeutic management. Oncogene. 2013; 32: 3009-18.

8. Jaiswal BS, Janakiraman V, Kljavin NM, EasthamAnderson J, Cupp JE, Liang Y, Davis DP, Hoeflich KP, Seshagiri S. Combined Targeting of BRAF and CRAF or BRAF and PI3K Effector Pathways Is Required for Efficacy in NRAS Mutant Tumors. PLoS ONE. 2009; 4: e5717.

9. Grimaldi AM, Simeone E, Ascierto PA. The role of MEK inhibitors in the treatment of metastatic melanoma. Curr Opin Oncol. 2014; 26: 196-203.

10. Vujic I, Posch C, Sanlorenzo M, Yen AJ, Tsumura A, Kwong A, Feichtenschlager V, Lai K, Arneson DV, Rappersberger K, Ortiz-Urda SM. Mutant NRAS Q61 shares signaling similarities across various cancer types - potential implications for future therapies. Oncotarget [Internet]. 2014 [cited 2014 Aug 20]; 5. Available from: http://www.impactjournals.com/oncotarget/index.php?j ournal $=$ oncotarget $\&$ page $=$ article $\&$ op $=$ view $\&$ path $\% 5 \mathrm{~B} \%$ $5 \mathrm{D}=2326$

11. Barretina J, Caponigro G, Stransky N, Venkatesan K, Margolin AA, Kim S, Wilson CJ, Lehár J, Kryukov GV, Sonkin D, Reddy A, Liu M, Murray L, et al. The Cancer Cell Line Encyclopedia enables predictive modelling of anticancer drug sensitivity. Nature. 2012; 483: 603-7.

12. Posch C, Moslehi H, Feeney L, Green GA, Ebaee A, Feichtenschlager V, Chong K, Peng L, Dimon MT, Phillips T, Daud AI, McCalmont TH, LeBoit PE, et al. Combined targeting of MEK and PI3K/mTOR effector pathways is necessary to effectively inhibit NRAS mutant melanoma in vitro and in vivo. Proc Natl Acad Sci. 2013; 110: 4015-20.

13. Downward J. Targeting RAS signalling pathways in cancer therapy. Nat Rev Cancer. 2003; 3: 11-22.

14. Britten CD. PI3K and MEK inhibitor combinations: examining the evidence in selected tumor types. Cancer Chemother Pharmacol. 2013; 71: 1395-409.

15. LoRusso P, Shapiro G, Pandya SS, Kwak EL, Jones C, Belvin M, Musib LC, Crespigny A de, McKenzie M, Gates MR, Chan IT-C, Bendell JC. A first-in-human phase Ib study to evaluate the MEK inhibitor GDC-0973, combined with the pan-PI3K inhibitor GDC-0941, in patients with advanced solid tumors. J Clin Oncol [Internet]. 2012 [cited 2014 Feb 18]; 30. Available from: http://meetinglibrary. asco.org/content/94732-114

16. Bendell JC, Rodon J, Burris HA, Jonge M de, Verweij 
J, Birle D, Demanse D, Buck SSD, Ru QC, Peters M, Goldbrunner M, Baselga J. Phase I, Dose-Escalation Study of BKM120, an Oral Pan-Class I PI3K Inhibitor, in Patients With Advanced Solid Tumors. J Clin Oncol. 2012; 30: 282 90.

17. Britten $\mathrm{C}$, Wainberg $\mathrm{Z}$, Tabernero J, Alsina Maqueda M, Leong S, Sessa C, Millham R, Gallo J, Siu L, Brana I. 358 A Multi-arm Phase 1 Dose Escalation Study of Safety, Pharmacokinetics, and Pharmacodynamics of the Dual PI3K/mTOR Inhibitors PF-04691502 (oral) and PF05212384 (IV) in Combination with the MEK Inhibitor PD0325901 or Irinotecan in Patients with Advanced Cancer. Eur J Cancer. 2012; 48: 109.

18. Cerezo M, Tomic T, Ballotti R, Rocchi S. Is it time to test biguanide metformin in the treatment of melanoma? Pigment Cell Melanoma Res [Internet]. 2014 [cited 2014 Feb 18]. Available from: http://onlinelibrary.wiley.com/ doi/10.1111/pcmr.12267/full

19. Zhou G, Myers R, Li Y, Chen Y, Shen X, Fenyk-Melody J, Wu M, Ventre J, Doebber T, Fujii N, Musi N, Hirshman MF, Goodyear LJ, et al. Role of AMP-activated protein kinase in mechanism of metformin action. J Clin Invest. 2001; 108: 1167-74.

20. Mihaylova MM, Shaw RJ. The AMPK signalling pathway coordinates cell growth, autophagy and metabolism. Nat Cell Biol. 2011; 13: 1016-23.

21. Landman GWD, Kleefstra N, van Hateren KJJ, Groenier KH, Gans ROB, Bilo HJG. Metformin associated with lower cancer mortality in type 2 diabetes: ZODIAC- 16 . Diabetes Care. 2010; 33: 322-6.

22. Ko EM, Walter P, Jackson A, Clark L, Franasiak J, Bolac C, Havrilesky LJ, Secord AA, Moore DT, Gehrig PA, BaeJump V. Metformin is associated with improved survival in endometrial cancer. Gynecol Oncol. 2014; 132: 438-42.

23. Hakimi AA, Chen L, Kim PH, Sjoberg D, Glickman L, Walker MR, Russo P. The impact of metformin use on recurrence and cancer-specific survival in clinically localized high-risk renal cell carcinoma. Can Urol Assoc J J Assoc Urol Can. 2013; 7: E687-91.

24. Nevadunsky NS, Van Arsdale A, Strickler HD, Moadel A, Kaur G, Frimer M, Conroy E, Goldberg GL, Einstein MH. Metformin use and endometrial cancer survival. Gynecol Oncol. 2014; 132: 236-40.

25. Gandini S, Puntoni M, Heckman-Stoddard BM, Dunn BK, Ford L, DeCensi A, Szabo E. Metformin and cancer risk and mortality: a systematic review and meta-analysis taking into account biases and confounders. Cancer Prev Res Phila Pa. 2014; 7: 867-85.

26. Chou T-C. Theoretical basis, experimental design, and computerized simulation of synergism and antagonism in drug combination studies. Pharmacol Rev. 2006; 58: 62181.

27. Giovannucci E, Harlan DM, Archer MC, Bergenstal RM, Gapstur SM, Habel LA, Pollak M, Regensteiner JG, Yee
D. Diabetes and Cancer A consensus report. Diabetes Care. 2010; 33: 1674-85.

28. Hosono K, Endo H, Takahashi H, Sugiyama M, Sakai E, Uchiyama T, Suzuki K, Iida H, Sakamoto Y, Yoneda K, Koide T, Tokoro C, Abe Y, et al. Metformin suppresses colorectal aberrant crypt foci in a short-term clinical trial. Cancer Prev Res Phila Pa. 2010; 3: 1077-83.

29. Quinn BJ, Kitagawa H, Memmott RM, Gills JJ, Dennis PA. Repositioning metformin for cancer prevention and treatment. Trends Endocrinol Metab TEM. 2013; 24: 46980.

30. Tomic T, Botton T, Cerezo M, Robert G, Luciano F, Puissant A, Gounon P, Allegra M, Bertolotto C, Bereder J-M, Tartare-Deckert S, Bahadoran P, Auberger P, et al. Metformin inhibits melanoma development through autophagy and apoptosis mechanisms. Cell Death Dis. 2011; 2: e199.

31. Janjetovic K, Harhaji-Trajkovic L, Misirkic-Marjanovic M, Vucicevic L, Stevanovic D, Zogovic N, SumaracDumanovic M, Micic D, Trajkovic V. In vitro and in vivo anti-melanoma action of metformin. Eur J Pharmacol. 2011; 668: 373-82.

32. Martin MJ, Hayward R, Viros A, Marais R. Metformin accelerates the growth of BRAF V600E-driven melanoma by upregulating VEGF-A. Cancer Discov. 2012; 2: 344-55.

33. Yuan P, Ito K, Perez-Lorenzo R, Guzzo CD, Lee JH, Shen C-H, Bosenberg MW, McMahon M, Cantley LC, Zheng B. Phenformin enhances the therapeutic benefit of BRAFV600E inhibition in melanoma. Proc Natl Acad Sci. 2013; 110: 18226-18231.

34. Esteve-Puig R, Canals F, Colomé N, Merlino G, Recio JÁ. Uncoupling of the LKB1-AMPK $\alpha$ Energy Sensor Pathway by Growth Factors and Oncogenic BRAFV600E. PLoS ONE. 2009; 4: e4771.

35. Choudhury Y, Yang Z, Ahmad I, Nixon C, Salt IP, Leung HY. AMP-activated protein kinase (AMPK) as a potential therapeutic target independent of PI3K/Akt signaling in prostate cancer. Oncoscience. 2014; 1: 446-56.

36. Lau Y-KI, Du X, Reyannavar V, Hopkins B, Shaw J, Bessler E, Thomas T, Pires MM, Keniry M, Parsons RE, Cremers S, Szabolcs M, Maurer MA. Metformin and erlotinib synergize to inhibit basal breast cancer. Oncotarget [Internet]. 2014 [cited 2014 Nov 4]; 5. Available from: http://www.impactjournals.com/oncotarget/index.php?j ournal $=$ oncotarget $\&$ page $=$ article $\&$ op $=$ view $\&$ path $\% 5 \mathrm{~B} \%$ $5 \mathrm{D}=2391$

37. Dupouy S, Doan VK, Wu Z, Mourra N, De Wever O, Penault Llorca F, Cayre A, Kouchkar A, Gompel A, Forgez P. Activation of EGFR, HER2 and HER3 by neurotensin/ neurotensin receptor 1 renders breast tumors aggressive yet highly responsive to lapatinib and metformin in mice. Oncotarget. 2014; 5: 8235-51.

38. Lin $\mathrm{Y}-\mathrm{C}, \mathrm{Wu} \mathrm{M}-\mathrm{H}$, Wei T-T, Lin Y-C, Huang W-C, Huang L-Y, Lin Y-T, Chen C-C. Metformin sensitizes 
anticancer effect of dasatinib in head and neck squamous cell carcinoma cells through AMPK-dependent ER stress. Oncotarget. 2014; 5: 298-308.

39. Niehr F, Euw E von, Attar N, Guo D, Matsunaga D, Sazegar H, Ng C, Glaspy JA, Recio JA, Lo RS, Mischel PS, CominAnduix B, Ribas A. Combination therapy with vemurafenib (PLX4032/RG7204) and metformin in melanoma cell lines with distinct driver mutations. J Transl Med. 2011; 9: 76.

40. Ascierto PA, Schadendorf D, Berking C, Agarwala SS, van Herpen CM, Queirolo P, Blank CU, Hauschild A, Beck JT, St-Pierre A, Niazi F, Wandel S, Peters M, et al. MEK162 for patients with advanced melanoma harbouring NRAS or Val600 BRAF mutations: a non-randomised, open-label phase 2 study. Lancet Oncol. 2013; 14: 249-56.

41. Nazarian R, Shi H, Wang Q, Kong X, Koya RC, Lee H, Chen Z, Lee M-K, Attar N, Sazegar H, Chodon T, Nelson $\mathrm{SF}, \mathrm{McArthur} \mathrm{G}$, et al. Melanomas acquire resistance to B-RAF(V600E) inhibition by RTK or N-RAS upregulation. Nature. 2010; 468: 973-7.

42. Hatzivassiliou G, Liu B, O’Brien C, Spoerke JM, Hoeflich KP, Haverty PM, Soriano R, Forrest WF, Heldens S, Chen H, Toy K, Ha C, Zhou W, et al. ERK Inhibition Overcomes Acquired Resistance to MEK Inhibitors. Mol Cancer Ther. 2012; 11: 1143-54.

43. Sun C, Hobor S, Bertotti A, Zecchin D, Huang S, Galimi F, Cottino F, Prahallad A, Grernrum W, Tzani A, Schlicker A, Wessels LFA, Smit EF, et al. Intrinsic Resistance to MEK Inhibition in KRAS Mutant Lung and Colon Cancer through Transcriptional Induction of ERBB3. Cell Rep. 2014; 7: 86-93.

44. Atefi M, von Euw E, Attar N, Ng C, Chu C, Guo D, Nazarian R, Chmielowski B, Glaspy JA, Comin-Anduix B, Mischel PS, Lo RS, Ribas A. Reversing Melanoma CrossResistance to BRAF and MEK Inhibitors by Co-Targeting the AKT/mTOR Pathway. PLoS ONE. 2011; 6: e28973.

45. Frid A, Sterner GN, Löndahl M, Wiklander C, Cato A, Vinge E, Andersson A. Novel assay of metformin levels in patients with type 2 diabetes and varying levels of renal function: clinical recommendations. Diabetes Care. 2010; 33: 1291-3.

46. Sandulache VC, Hamblin JS, Skinner HD, Kubik MW, Myers JN, Zevallos JP. Association between metformin use and improved survival in patients with laryngeal squamous cell carcinoma. Head Neck. 2014; 36: 1039-43.

47. Wilcock C, Bailey CJ. Accumulation of metformin by tissues of the normal and diabetic mouse. Xenobiotica. 1994; 24: 49-57.

48. Owen MR, Doran E, Halestrap AP. Evidence that metformin exerts its anti-diabetic effects through inhibition of complex 1 of the mitochondrial respiratory chain. Biochem J. 2000; 348: 607-14.

49. Carvalho C, Correia S, Santos MS, Seiça R, Oliveira $\mathrm{CR}$, Moreira PI. Metformin promotes isolated rat liver mitochondria impairment. Mol Cell Biochem. 2008; 308:
$75-83$.

50. Algire C, Zakikhani M, Blouin M-J, Shuai JH, Pollak M. Metformin attenuates the stimulatory effect of a highenergy diet on in vivo LLC1 carcinoma growth. Endocr Relat Cancer. 2008; 15: 833-9.

51. Memmott RM, Mercado JR, Maier CR, Kawabata S, Fox $\mathrm{SD}$, Dennis PA. Metformin prevents tobacco carcinogen-induced lung tumorigenesis. Cancer Prev Res Phila Pa. 2010; 3: 1066-76. 